Editorial

\title{
Adapted Physical Activity through COVID-19
}

\author{
Kwok Ng 1,2 \\ Submitted 23 ${ }^{\text {rd }}$ April 2020; Reviewed 26 ${ }^{\text {th }}$ April 2020; Published: $29^{\text {th }}$ April 2020
}

The COVID-19 pandemic has affected everyone in some way or other, and particularly those populations specified as vulnerable and at risk, including those with disabilities. At the time of writing, the number of cases and deaths keep on rising in most parts of the world, thereby creating the worst pandemic for over 100 years. On the $12^{\text {th }}$ January 2020, Chinese officials shared the genetic sequence of COVID-19 (WHO, 2020). Since then, there has been a surge in collaborative research across the globe to answer some of the important questions about the transmission of COVID-19 between humans, the symptoms of infection, the carriage of the virus in sewage, ways to test and diagnosis COVID-19, the appropriate treatments of infected individuals, creation of vaccines, as well as better understanding of the origin of the virus (Yuen, Ye, Fung, Chan, \& Jin, 2020). Amidst the global vocational and economic crisis, people from all around the world still converge virtually and build solutions through weekly hackathons, speeding up of traditional research and development techniques. Meanwhile, the majority of the public experience the reduction of physical interaction through social distancing and the closure of public gatherings, including sports events, concerts, restaurants as well as schools. This has placed a large burden on families, whereby parents and children stay in the same home for the entire day, rather than the 'usual' commute to work and school. Despite such changes to everyone's routine, whether infected or not, this behavioural aspect has received low levels of attention by policymakers, especially from the perspective of physical activity (PA) promotion, let alone with adapted physical activity (APA).

\section{Staying physically active}

PA is the cheapest medicine in the world, whereby regular participation of PA has constantly shown to prevent the risks of non-communicable diseases, improve physical functioning and mental health (2018 Physical Activity Guidelines Advisory Committee, 2018). Moreover, research has demonstrated that taking part in cardiovascular exercises can improve immunity protection due to the use of the same respiratory muscles that are attacked by the virus (Laddu, Lavie, Phillips, \& Arena, 2020). There has been an increase in the amount of online fitness channels produced to help individuals participate in guided exercise, through a programme that is safe, simple and easy to implement (Chen et al., 2020). In some way, PA conducted at home is adapted. There is a basic assumption that the adaptations are mainly in the form of adapting equipment, space, and task difficulty, for example modifying exercises for people who are unable to jump and stand, yet the style of communication is often overlooked and not adapted. Emerging evidence emphases a motivationally adaptive communication style is needed to improve exerciser satisfaction (Ntoumanis, Thøgersen-Ntoumani, Quested, \& Hancox, 2017), but not all instructors have been trained. Telehealth systems need to be in place to ensure patients who normally receive community level care to maintain their exercises needed to improve functioning for daily activities (Falvey, Krafft, \& Kornetti, 2020). Traditional recorded media allows individuals can replay the programmes at the user's own convenience, but feedback from the instructor to motivate, correct or adjust can be random and it lacks the individualised methods that are typical for APA. There has been a wide uptake on programmes like Zoom for online guided 
exercise and instructors can give live feedback to the otherwise unidirectional online options from platforms like YouTube. Specific programmes, such as the Exercise Buddy app have been designed to support people with autism to be physically active using evidence-based practices such as video models, visual supports, social narratives, technology aided instruction and exercises. Although it is not free, it is certainly worth every penny of it given the benefits of exercise, motor control and confidence that comes from such a programme.

\section{Staying physically educated}

Adapted Physical Education (APE) has been based on the hands-on interactions between students and teachers. The closures of schools and the immediate transfer to online teaching has brought challenges to teachers to conduct remote lessons. The technology has a broad reach as $97 \%$ of the EU has broadband coverage in 2018, however only $57 \%$ of the population have at least the basic digital skills (European Commission, 2019) indicating a large skills gap, with physical education (PE) teachers likely to be in need too. There is an urgent demand for online educational support and more research to address adaptation (or adaptive) strategies that PE teachers utilize while engaging in online instruction. Multiple social media platforms have created a collaborative effort to provide guides for teachers to teach PE lessons remotely. The advances of available technology allow teaching options to group children into different virtual rooms with smaller group interactions, which may be used to observe and provide personalised feedback. Teachers may then create supplementary individualised sessions for those who have difficulties with the general instruction sessions. This may be part of the solution, it does not escape from the need of working with a teacher assistant. PE needs to remain on the remote study individualised education plan, with teachers active in designing alternative instructions and lessons that promote physical and social activity from PE, and it may be supported by software (McNamara \& Dillon, 2020). Children with disabilities are largely at a disadvantage and may end up feeling excluded in this otherwise connected cyberspace when teachers do not sufficiently plan their lessons. Previous advocacy work in APE to include children with disabilities into PE needs to continue so that teachers can continue to find ways to provide high quality PE to all children in their class, even when it is done remotely.

\section{Staying connected with research and practice}

As the restrictions are slowly removed, the APA community of researchers and practitioners need to be prepared to do their part in ensuring the COVID-19 pandemic exit strategies addresses PA as a protective strategy, particularly for people with disabilities, who are more vulnerable to obesity, loneliness and depression than the general population. Researchers, practitioners and teachers will need to participate in continuous professional development through training, practical workshops, conferences and symposia. Opportunities of inspiration to people with and without disabilities from the Paralympic Games will need to be delayed as Tokyo 2020 is officially postponed until 2021 (International Paralympic Committee, 2020). Several APA conferences planned, including the EUCAPA Elche 2020 have been cancelled to ensure the health of individuals remains the highest priority. There are also options to postpone conferences, however extra considerations are needed for the uncertainty of when the pandemic ends, when the travel restrictions would be lifted, and how postponing the event brings challenges for other events in 2021. The APA community has opportunities to make use of available online tools to connect and the European organisers are investigating ways to hold virtual solutions for opportunities to learn, network and collaborate with each other. In addition to sharing practices, like the COVID-19 special focus within the What's new in Adapted Physical Education podcast series, the APA community needs to take charge in leading online events 
around the world that allows people to touch base and socialise in these isolated times when providing opportunities for people with disabilities to be physically active. This may forge new connections that bring people in APA closer together, something to look forward to, as the theme of ISAPA 2021 is to bring "Quality partnerships in APA" (Rintala, 2019).

\section{Author affiliations:}

1 School of Educational Sciences and Psychology, University of Eastern Finland, Finland. Kwok.ng@uef.fi

2 Physical Activity for Health research cluster, Department of Physical Education and Sport Sciences, University of Limerick, Limerick, Ireland

\section{References}

2018 Physical Activity Guidelines Advisory Committee. (2018). 2018 Physical activity guidelines advisory committee scientific report. Washington DC: US: Department of Health and Human Services. Retrieved from https://health.gov/sites/default/files/201909/PAG_Advisory Committee Report.pdf

Chen, P., Mao, L., Nassis, G. P., Harmer, P., Ainsworth, B. E., \& Li, F. (2020). Coronavirus disease (COVID-19): The need to maintain regular physical activity while taking precautions. Journal of Sport and Health Science, 9(2), 103-4. https://doi.org/10.1016/j.jshs.2020.02.001

European Commission. (2019). The digital economy and society index (DESI). Retrieved from https://ec.europa.eu/digital-single-market/en/desi

Falvey, J. R., Krafft, C., \& Kornetti, D. (2020). The essential role of home- and community-based physical therapists during the COVID-19 pandemic. Physical Therapy, pzaao69. https://doi.org/10.1093/ptj/pzaa069

International Paralympic Committee. (2020). IPC reaction: Tokyo 2020 Paralympic Games postponed. Retrieved from https://www.paralympic.org/news/ipc-reaction-tokyo-2020paralympic-games-postponed

Laddu, D. R., Lavie, C. J., Phillips, S. A., \& Arena, R. (2020). Physical activity for immunity protection: Inoculating populations with healthy living medicine in preparation for the next pandemic. Progress in Cardiovascular Diseases, YPCAD-01079. https://doi.org/10.1016/j.pcad.2020.04.006

McNamara, S., \& Dillon, S. (2020). Finding a home for adapted physical education in individualized education program software. European Journal of Adapted Physical Activity, 13, 4. https://doi.org/10.5507/euj.2019.015

Ntoumanis, N., Thøgersen-Ntoumani, C., Quested, E., \& Hancox, J. (2017). The effects of training group exercise class instructors to adopt a motivationally adaptive communication style. Scandinavian Journal of Medicine \& Science in Sports, 27(9), 1026-1034. https://doi.org/10.1111/sms.12713

Rintala, P. (2019). Quality partnerships in adapted physical activity. European Journal of Adapted Physical Activity, 12, 7. https://doi.org/10.5507/euj.2019.012

WHO. (2020). WHO timeline COVID-19. Retrieved from https://www.who.int/newsroom/detail/o8-04-2020-who-timeline---covid-19

Yuen, K-S., Ye, Z-W., Fung, S-Y., Chan, C-P, \& Jin, D-Y. (2020). SARS-CoV-2 and COVID-19: The most important research questions. Cell \& Bioscience, $10(1), 40$. https://doi.org/10.1186/s13578-020-00404-4

(C) 2020 by the authors. Submitted for possible open access publication under the terms and conditions of the Creative Commons Attribution (CC BY) license (http://creativecommons.org/licenses/by/4.o/). 